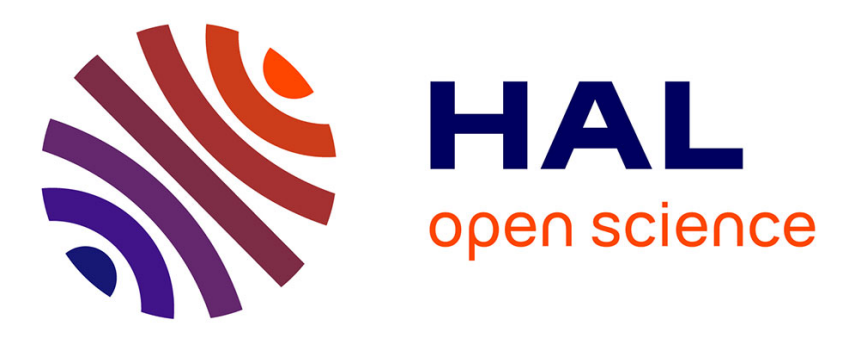

\title{
Integrated Class-D audio amplifier virtual test for output EMI filter performance
}

Roberto Mrad, Florent Morel, Gaël Pillonnet, Christian Vollaire, Angelo

Nagari

\section{- To cite this version:}

Roberto Mrad, Florent Morel, Gaël Pillonnet, Christian Vollaire, Angelo Nagari. Integrated Class-D audio amplifier virtual test for output EMI filter performance. Conference on $\mathrm{Ph}$. D. Research in Microelectronics and Electronics, IEEE, Jun 2013, Villach, Austria. pp.4, 10.1109/PRIME.2013.6603127 . hal-01103590

\section{HAL Id: hal-01103590 \\ https://hal.science/hal-01103590}

Submitted on 16 Jan 2015

HAL is a multi-disciplinary open access archive for the deposit and dissemination of scientific research documents, whether they are published or not. The documents may come from teaching and research institutions in France or abroad, or from public or private research centers.
L'archive ouverte pluridisciplinaire HAL, est destinée au dépôt et à la diffusion de documents scientifiques de niveau recherche, publiés ou non, émanant des établissements d'enseignement et de recherche français ou étrangers, des laboratoires publics ou privés. 


\title{
Integrated Class-D Audio Amplifier Virtual Test for Output EMI Filter Performance
}

\author{
Roberto Mrad*†‡, Florent Morel*, Gael Pillonnet ${ }^{\dagger}$, Christian Vollaire* and Angelo Nagari ${ }^{\ddagger}$ \\ *University of Lyon, ECL \\ Ampere, CNRS UMR5005, 36 avenue Guy de Collongue, 69134 Ecully, France \\ Email: firstname.lastname@ec-lyon.fr \\ †University of Lyon, CPE \\ INL, CNRS UMR5270, 43 bd de 11 Novembre 1918, 69616 Villeurbanne, France \\ Email: firstname.lastname@cpe.fr \\ ${ }^{\ddagger}$ ST Ericsson, Grenoble, France \\ Email: firstname.lastname@stericsson.com
}

\begin{abstract}
This paper proposes a model based on the segmentation technique that can be used for electromagnetic interference (EMI) filter test by simulation. It is dedicated for systems with a differential output. The present approach proposes virtual measurement of the filter performance in the final application. Thus, the source emissions and the load impedance are taken into account. The proposed approach uses impedance matrices to model the passive parts of the system. A matrix calculation permits to associate these matrices and create a compact model. The impedance matrices and the converter output voltages are used for currents and voltages calculation at all the system points. Finally, the proposed method is applied and validated on a Class-D amplification system. This method shows good accuracy on the $[1 \mathrm{kHz}-120 \mathrm{MHz}]$ frequency band.
\end{abstract}

Index Terms-Integrated Class-D amplifier, Electromagnetic compatibility, EMI modelling, Filter design, Impedance matrix.

\section{INTRODUCTION}

In embedded systems, battery life is a major issue. Thus, switching power management circuits are generally used thanks to their power efficiency. For loudspeaker audio applications, integrated Class-D amplifiers are a good trade off between power efficiency and audio quality. However, such switching circuits, generates serious ElectroMagnetic (EM) disturbances for the surrounding electronics. Therefore, designers use control techniques, such as spread spectrum [1][4], slew rate control [5], [6], pulse position [7] to reduce the power converter emissions. However, these techniques effects on the low and medium frequency range. Therefore, an ElectroMagnetic Interference (EMI) filter is inserted between the filter and the load (loudspeaker) in order to reduce the high frequency emissions in the Printed Circuit Board (PCB) track.

EMI filters are made from bulky and costly passive components. Fig. 1 shows a Class-D amplifier and an EMI filter in a smart-phone application. As can be seen, the filter can occupy an area on PCB twice the one occupied by the amplifier chip itself. Thus, the filter components should be well chosen so it will not be over-dimensioned. Moreover, High frequency EMI filter response strongly depends on components and PCB stray elements. Therefore, when studying ElectroMagnetic Compatibility (EMC) of such systems and filters, designers rely on



Fig. 1. Class-D amplifier and an EMI filter in the final application.

prototypes and measurements. Hence, a method helping the EMI filter design before production can reduce the production time and cost.

In previous works, a method has been presented in [8], [9]. The latter allows to model a Class-D amplification system in the frequency domain in order to calculate the spectra of the amplifier output currents which are the same as the filter input currents (see Fig. 2 and Fig. 3). The method consists on decomposing the system into separate blocks and model the passive ones by impedance matrices. Hereafter, the blocks are concatenated to reconstitute the system into a compact model represented by a single impedance matrix. Finally, using the resulting matrix and the amplifier output voltages, the amplifier output current spectra are calculated. There are many advantages for this method. First, this method takes into account the load impedance and source emissions to predict the filter behavior in the final application. Second, it takes into account the Common Mode (CM), the Differential Mode (DM) and the mode conversion. Third, it has a good accuracy at high frequencies and it has a short simulation time compared to transient simulations.

This paper extends the method presented above in order to calculate the currents and voltages at the EMI filter output. Thus, the filter EMI performance can be evaluated.

Section II presents the method principles as well as the required theory details. Section III presents an experimental application on a Class-D amplifier system and discuss the results. Finally, section IV concludes the paper and proposes some perspectives. 


\section{MODELING APPROACH}

\section{A. Frequency model}

The system in use is shown in Fig. 2. It contains a Class-D amplifier, an EMI filter and a speaker load. The considered approach lies on decomposing the system into functional blocks as shown in Fig. 3. The passive blocks are modeled by impedance matrices which relate the block voltages to the block currents as shown in (1).

$$
\left(\begin{array}{c}
V_{1} \\
\vdots \\
V_{N}
\end{array}\right)=\left(\begin{array}{ccc}
z_{11} & \cdots & z_{1 N} \\
\vdots & \ddots & \vdots \\
z_{N 1} & \cdots & z_{N N}
\end{array}\right)_{(N \times N)} \cdot\left(\begin{array}{c}
I_{1} \\
\vdots \\
I_{N}
\end{array}\right)
$$

Since integrated Class-D amplifiers have a H-bridge output power stage, a $4 \times 4$ impedance matrix is needed to model the filter which correspond to 4-port block (two ports for the inputs and two others for the outputs). However, the speaker load have only two electrical input ports and an acoustic output. Thus, the speaker is modeled by a $2 \times 2$ impedance matrix which correspond to a 2-port block. The impedance matrix can be determined using an impedance analyzer [8], a vector network analyzer or by electrical simulation, such as Advanced System Design (ADS) for Agilent.

Once the impedance matrices of the filter and the load are determined, (2) is used to merge the two matrices [8].

$$
Z_{R}=Z_{F 11}-Z_{F 12}\left(Z_{L}+Z_{F 22}\right)^{-1} Z_{F 21}
$$

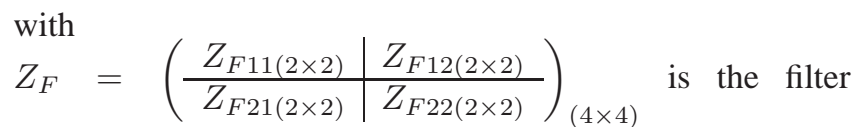
impedance matrix, $Z_{L(2 \times 2)}$ is the load impedance matrix, $Z_{R}$ is the a resulting $2 \times 2$ impedance matrix modeling all the passive blocks of the system.

Note that, if the amplifier output impedance is not negligible, it should be concatenated with the rest of the passive blocks [9]. Note as well that, the filter, load and resulting matrix are symmetric with respect to the diagonal $\left(Z_{i j}=Z_{j i} ; i=1 \ldots 4 ; j=1 \ldots 4 ; i \neq j\right)$ due to the reciprocity theorem.

Due to the differential output, the Class-D amplifier is modeled by two AC voltage sources and an impedance matrix to model the converter output impedance as shown in Fig. 4. However, in this case, the amplifier output impedance is negligible compared to the filter and load impedance over the considered frequency range. It has been tested by measuring the converter output voltages with different loads: open circuit, speaker and speaker with EMI filter. In the three cases the output voltages remains unchanged. Determining the AC voltage sources can be done by measurement or by simulation. In case of measurements, the two voltages should be measured in the time domain at the same time to obtain a correct phase between them, then a FFT convert them to the frequency domain.

\section{B. Currents and voltages calculation}

Using the amplifier model, the filter matrix, the load matrix and the resulting matrix, it is possible to calculate all the

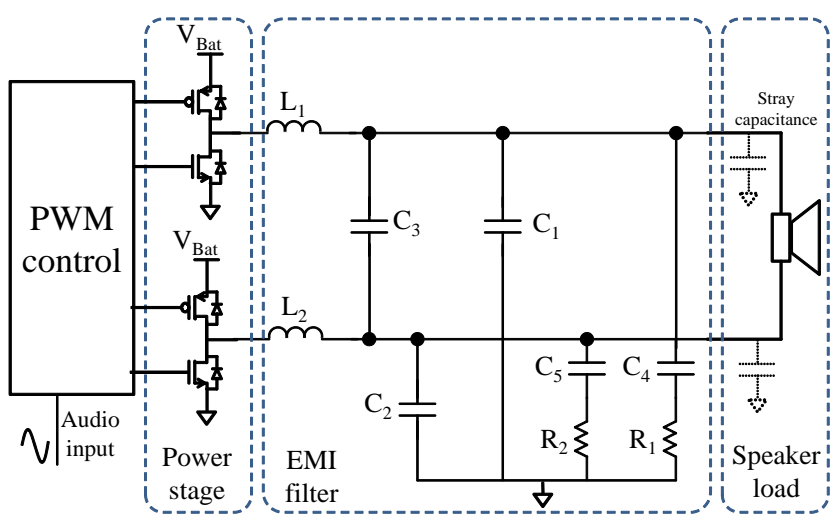

Fig. 2. Considered Class D amplifier system.

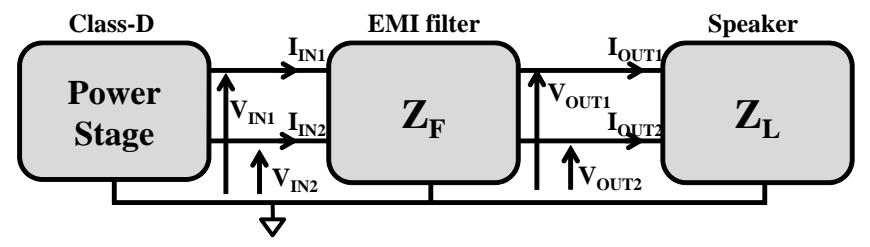

Fig. 3. Amplification system bloc diagram.

spectra of the currents and voltages in the system. Thus, the filter and load can be evaluated in terms of EMI.

Equation (3) permits to calculate the currents at the converter output (same as the filter input) [9].

$$
\left(\begin{array}{c}
I_{I N 1} \\
I_{I N 2}
\end{array}\right)=\left(Z_{R}\right)^{-1}\left(\begin{array}{c}
V_{I N 1} \\
V_{I N 2}
\end{array}\right)
$$

Where $V_{I N 1}, V_{I N 2}$ are the amplifier output voltages, $I_{I N 1}$, $I_{I N 2}$ are the amplifier output currents and $Z_{R}$ is the filter and speaker resulting impedance matrix computed using (2).

The output voltages $\left(V_{O U T 1}, V_{O U T 2}\right)$ and currents $\left(I_{O U T 1}\right.$, $\left.I_{O U T 2}\right)$ can be calculated using equation (4) and (5) respectively.

$$
\begin{gathered}
\left(\begin{array}{c}
V_{\text {OUT1 }} \\
V_{\text {OUT2 }}
\end{array}\right)=\left(I+Z_{F 22} Z_{L}^{-1}\right)^{-1} Z_{F 21} Z_{R}^{-1}\left(\begin{array}{c}
V_{I N 1} \\
V_{I N 2}
\end{array}\right) \\
\left(\begin{array}{c}
I_{\text {OUT } 1} \\
I_{\text {OUT2 }}
\end{array}\right)=Z_{L}^{-1}\left(\begin{array}{c}
V_{\text {OUT } 1} \\
V_{\text {OUT2 }}
\end{array}\right)
\end{gathered}
$$

Where $V_{I N 1}, V_{I N 2}$ and $V_{O U T 1}, V_{O U T 2}$ are the filter input and output voltages respectively, $I_{O U T 1}, I_{O U T 2}$ are the filter output currents, $I$ is a $2 \times 2$ eye matrix, $Z_{F}$ is the filter matrix presented above, $Z_{L}$ is the load matrix and $Z_{R}$ is the resulting matrix.

The proof of equation (4) can explained as follow.

By definition (see Fig. 3):

$$
\begin{aligned}
\left(\begin{array}{c}
V_{I N 1} \\
V_{I N 2}
\end{array}\right) & =Z_{F 11}\left(\begin{array}{c}
I_{I N 1} \\
I_{I N 2}
\end{array}\right)+Z_{F 12}\left(\begin{array}{c}
I_{\text {OUT1 }} \\
I_{\text {OUT2 }}
\end{array}\right) \\
\left(\begin{array}{c}
V_{\text {OUT1 }} \\
V_{\text {OUT2 }}
\end{array}\right) & =Z_{F 21}\left(\begin{array}{c}
I_{I N 1} \\
I_{I N 2}
\end{array}\right)-Z_{F 22}\left(\begin{array}{c}
I_{O U T 1} \\
I_{\text {OUT2 }}
\end{array}\right)
\end{aligned}
$$






Fig. 4. Amplifier frequency domain model.

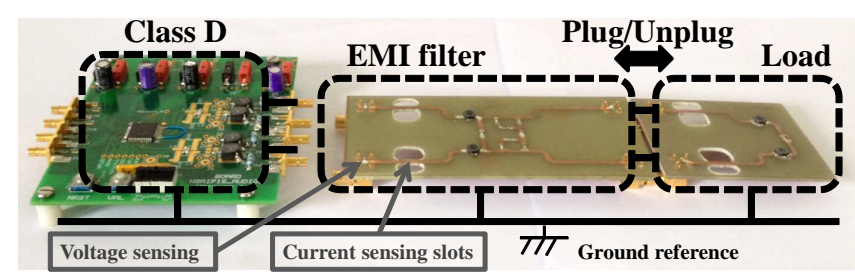

Fig. 5. Boards used for method validation.

In (7), $\left(\begin{array}{c}I_{I N 1} \\ I_{I N 2}\end{array}\right)$ and $\left(\begin{array}{c}I_{O U T 1} \\ I_{O U T 2}\end{array}\right)$ can be replaced using equation (3) and 5. Thus, equation (4) can be calculated.

\section{APPLICATION}

The method presented in section II is applied on amplification system for validation. The amplifier itself is a Class-D type amplifier controlled with a Pulse Width Modulation (PWM). The filter in use is a common structure for Class-D amplifiers and presented in [10]. The filter schematic is the same as the one shown in Fig. 2. The load is a dummy load which is equivalent to a loudspeaker used in cellphone applications. It contains two coils of $15 \mu H$ and an $8 \Omega$ resistor. The three system parts are mounted on separate printed circuit boards, equipped with SMB connectors for an easy association/disassociation with a simple plug/unplug. Moreover, the boards are designed for an easy currents and voltages sensing on the filter and load inputs as shown in Fig. 5.

The filter and the load were simulated using ADS. Passive components were replaced by models from suppliers libraries dedicated to ADS environment. Thus, the high frequency component behavior is taken into account. PCB tracks are modeled by strip-lines and the PCB material values are included in the model. Thus, the impedance of the PCB tracks and the PCB layout are taken into account. Finally, the filter and load impedance matrices were obtained which are called $Z_{F}$ and $Z_{L}$ respectively. Using (2) the filter and load were concatenated into $Z_{R}$, the resulting matrix.

A test-bench was placed in an anechoic chamber to reduce the environmental noise. Then, a 12-bit quantization oscilloscope is used to measure the amplifier output voltages at the same time. Hereafter a FFT transforms the time domain signals into the frequency domain. In Fig. 6, the measurement noise floor is lower than the voltage spectrum over the entire frequency band. Thus, the voltages are valid to be used in the

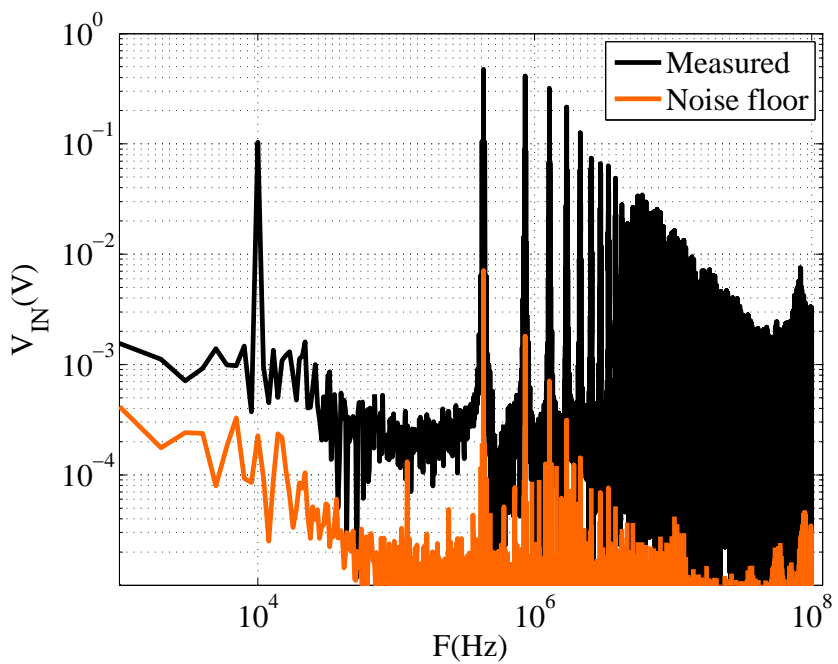

Fig. 6. The Class-D amplifier input voltage measured.

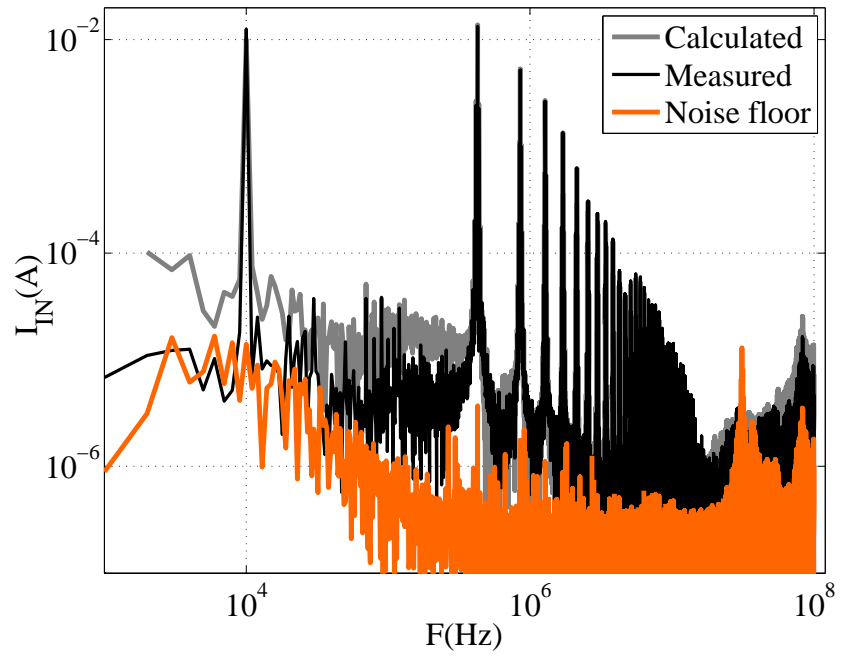

Fig. 7. Calculated and measured input current.

calculation. Therefore, $Z_{F}, Z_{L}, Z_{R}$, and the measured input voltages were used in equation (3), equation (4) and equation (5) to calculate the input current, the output voltages and the output current respectively. Note that, the input currents and the output current and voltage are measured to be compared with the calculated ones. As the current probe used for current measurement has a bandwidth of $[1 \mathrm{kHz}-120 \mathrm{M} \mathrm{Hz}]$, Fig. 7, Fig. 8 and Fig. 9 shows the results up to $120 \mathrm{MHz}$.

Fig. 7 shows that the calculated input current have a good accordance with the measured one on the considered frequency range. The only difference between the two spectra is an extra peak at $30 \mathrm{M} \mathrm{Hz}$ in case of measurement and this is due to the current noise floor. However, in Fig. 8 the calculated output voltage have a good accordance with the measured one up to $6 \mathrm{MHz}$; this is due to the the noise floor for voltage measurement. The instrumentation in use do not allow to do voltage measurements below than $15 \mu \mathrm{V}$. Finally, Fig 9 shows as well that the instrumentation in use do not allow any current measurement below $0.5 \mu \mathrm{A}$, thus the calculated 


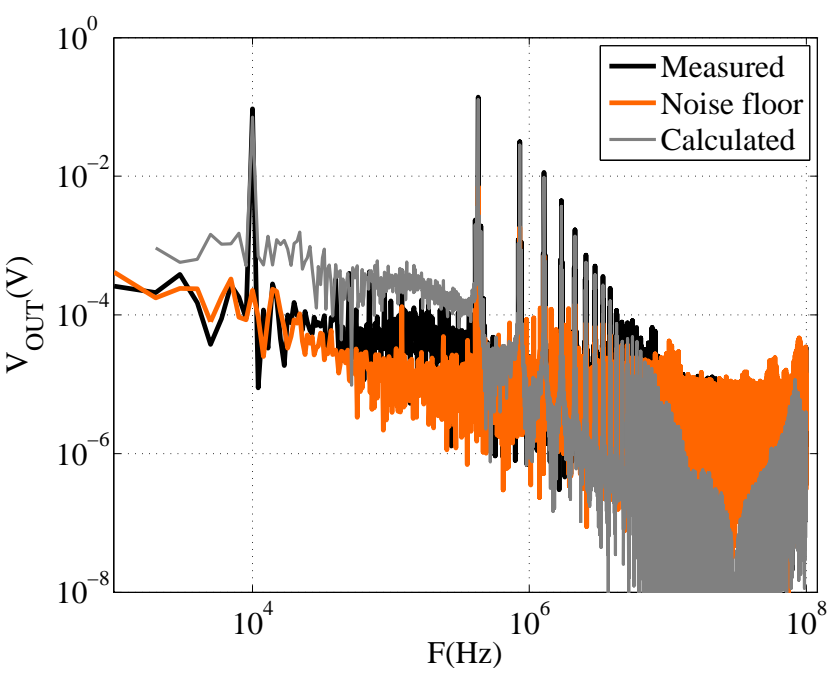

Fig. 8. Calculated and measured output voltage.



Fig. 9. Calculated and measured output current.

current is in a good accordance with the measured one up to $2 M H z$. The output voltages and currents cannot be validated beyond $6 \mathrm{M} \mathrm{Hz}$ and $2 \mathrm{MHz}$ respectively, because they cannot be compared to the measurements due to the measurement noise floor.

\section{CONCLUSION}

A modeling method in the frequency domain was presented. It is dedicated to EMI virtual measurements for integrated Class-D amplifiers which have a differential output. The system is decomposed into blocks, where the passive blocks are modeled with impedance matrices and active blocks such as Class-D amplifiers are modeled with $\mathrm{AC}$ voltage sources and an impedance matrix if needed. Once determined, the impedance matrices are concatenated in order to obtain a compact model for the system. The impedance matrices and the converter output voltages can be used for current and voltages calculation in all the system points.
The approach is applied on a Class-D amplification system for validation. Good results are seen over the frequency ranges where the signal levels are greater than the noise floor. However, if the signal is lower than the noise floor, it means that the current is lower than $0.5 \mu \mathrm{A}$ or the voltage is lower than $15 \mu \mathrm{V}$. In these conditions, the EM emissions of the system have a very low impact on the surrounding electronics. Thus, the present method can still be helpful in EMI filter design.

The present approach allows system designers to take into account the EMI at the design stage. It is possible to make a library of blocks which can lead the EMI studies at the early development. Otherwise, this method have a short simulation time. Thus, it can be integrated in an optimization process for filter improvement.

The future work will be focused on developing and optimization process that uses this method for filter improvement.

\section{REFERENCES}

[1] A. Nagari, E. Allier, F. Amiard, V. Binet, and C. Fraisse, "An $8 \Omega$; $2.5 \mathrm{~W} 1 \%$-THD $104 \mathrm{~dB}(\mathrm{~A})$-dynamic-range Class-D audio amplifier with an ultra-low EMI system and current sensing for speaker protection," in Solid-State Circuits Conference Digest of Technical Papers (ISSCC), 2012 IEEE International, feb. 2012, pp. $92-94$.

[2] M.-L. Yeh, W.-R. Liou, H.-P. Hsieh, and Y.-J. Lin, "An electromagnetic interference (EMI) reduced high-efficiency switching power amplifier," Power Electronics, IEEE Transactions on, vol. 25, no. 3, pp. $710-718$, mar. 2010.

[3] M. Xin, C. Zao, Z. Ze-kun, and Z. Bo, "An advanced spread spectrum architecture to improve EMI emissions in Class D amplifier," in Communications, Circuits and Systems, 2009. ICCCAS 2009. International Conference on, jul. 2009, pp. $661-665$.

[4] G. Dousoky, M. Shoyama, and T. Ninomiya, "On factors affecting EMIperformance of conducted-noise-mitigating digital controllers in DCDC converters - An experimental investigation," in Energy Conversion Congress and Exposition (ECCE), 2010 IEEE, sept. 2010, pp. 1239 1245.

[5] C. F. Edwards, "Efficient low EMI switching output stages and methods," no. US 7190225, mar. 2007, patent : US 7190225.

[6] T. Lim, H. Muir, S. Finney, and B. Williams, "Adaptive voltage slew control used to limit the magnitude of broadband conducted noise emissions for buck derived dc-dc converters," in Electromagnetic Compatibility (APEMC), 2012 Asia-Pacific Symposium on, may 2012, pp. 93 -96.

[7] T. Nakagawa and K. Osada, "Pulse position/width collaborative control for reducing EMI noise and ripple voltage in switching DC-DC converter," in Applied Power Electronics Conference and Exposition (APEC), 2012 Twenty-Seventh Annual IEEE, feb. 2012, pp. $1112-1116$.

[8] R. Mrad, F. Morel, G. Pillonnet, C. Vollaire, and D. Labrousse, "Differential passive circuit modelling with pentapole impedance matrices - application to an integrated audio switching amplifier for portable devices," in EMC Europe 2011 York, sept. 2011, pp. 304 -309.

[9] R. Mrad, F. Morel, G. Pillonnet, C. Vollaire, and A. Nagari, "Conducted EMI prediction for integrated Class D audio amplifier," in Electronics, Circuits and Systems (ICECS), 2011 18th IEEE International Conference on, dec. 2011, pp. $390-393$.

[10] “MAXIM : MAX9700B Evaluation Kit,” accessed: 08/01/2012. 